\title{
LECTURA Y ANÁLISIS DE CUATRO MANUALES ESCOLARES DE LENGUA DE EDICIONES ARGENTINAS
}

\author{
María Victoria Goicoechea Gaona \\ Universidad Nacional del Comahue \\ Centro Regional Universitario Bariloche (Argentina)
}

\begin{abstract}
RESUMEN: El desarrollo de este trabajo se inscribe en el área de la didáctica de las lenguas y las literaturas y consiste en el análisis de cuatro manuales escolares de lengua de ediciones argentinas, realizado a partir de la teoría del Interaccionismo sociodiscursivo (Ginebra-Bariloche). Los cuatro textos estudiados se organizan en torno a géneros textuales habituales en el ámbito escolar, lo que evidencia que se trata de una noción fundamental para la enseñanza de la lengua. Sorprende que mientras la presencia de nociones discursivas es alta, la mayoría de los ejercicios propuestos a los alumnos se centra en las nociones gramaticales.
\end{abstract}

ABSTRACT: The development of this work is inserted in the area of Languages and Literatures Didactics, and consists in the analysis of four Language school texts edited in Argentin, and was performed starting from the Social-Discursive Interactionism/Social and Discoursive Interaccionism theory (Geneva-Bariloche). The four studied textbooks are organized around speech genres (textual genres) usual in the school field, what proves that this notion is fundamental in the teaching of Language. It is surprising that while the presence of discursive notions is high, most of the exercises proposed to the students is centered on gramatical notions.

PALABRAS CLAVE: Didáctica de la lengua, manuales escolares, educación primaria, género textual, actividad de lectura, actividad de escritura.

KEYWORDS: Didactics of the Language/Language Didactics, school texts, speech genres.

\section{INTRODUCCIÓN}

Con el surgimiento y auge de la escuela se plantea la necesidad de hacer accesible el conocimiento: enseñar a aprender (en los niveles primario y secundario) y enseñar a enseñar (nivel universitario). Para ello es necesario que la Didáctica, dis- 
ciplina del área de las Ciencias de la Educación, desarrolle y sistematice investigaciones en torno al sistema educativo y los procesos de formación para, de ese modo, centrar el análisis en la problemática de la eficacia de la enseñanza de una disciplina escolar (Riestra, 2008).

Partimos de lo planteado desde la psicología interaccionista que pone a la problemática didáctica en el centro de la preocupación del desarrollo humano, es decir, en relación con otras disciplinas como la psicología, la sociología y la lingüística. Además, entiende la didáctica como una de las disciplinas que integra el área de las Ciencias Humanas y, en consecuencia, necesita de un trabajo conjunto para lograr su objeto. Según Bronckart (en Riestra, ídem: 65), "los procesos de mediación formativa son elementos determinantes de la construcción y funcionamiento psicológico en general, no sólo de la construcción de conocimientos formales, sino de la construcción de las personas con el conjunto de sus dimensiones psicológicas, emocionales, afectivas, sociales, etc.". Por lo tanto, partimos de una concepción de la didáctica de las disciplinas escolares que considera "la problemática frente a un objeto complejo, que articula dimensiones específicas de saberes y de saber hacer en cuanto a la enseñanza, junto con las dimensiones generales de los procesos de formación, es decir, las condiciones de transmisión, de apropiación y de transformación de esos saberes." (ídem: 65).

En Didáctica de la lengua y la literatura (Briz, 1998) se han desarrollado modelos de enseñanza de la lengua oral y escrita centrados en enseñar a los niños habilidades lingüísticas y comunicativas (enfoque comunicativo) necesarias para desenvolverse apropiadamente en las situaciones sociales en las que puedan encontrarse. Se considera que el desarrollo de estas habilidades, "tanto en el procesamiento expresivo y comprensivo de textos orales (hablar y escuchar) como de textos escritos (leer y escribir), es importante porque estas habilidades contribuyen al desarrollo cognitivo y a la integración personal de los ciudadanos [...] es igualmente una preocupación social, ya que los procesos de comunicación en los ámbitos personal, familiar, profesional son básicos e instrumentales" (ídem: 115).

El alcance de este trabajo se circunscribe al nivel primario $y$, aunque nos ubiquemos en el área de la didáctica de las lenguas y las literaturas, será únicamente la lengua el objeto de estudio que se llevará a cabo mediante el análisis de cuatro manuales escolares destinados a la enseñanza de la lengua materna en Argentina. Por cuanto este trabajo nos permitirá adentrarnos en el sistema educativo argentino a través del material (manuales escolares) que avala y conocer las propuestas de trabajo que estos textos instalan en las aulas, consideramos importante señalar que algunas de las editoriales presentes con mucho peso en el país son de origen español, concretamente Santillana y SM. El resto, muy numerosas, son argentinas.

Para la elección del corpus se seleccionaron algunos de los libros más empleados en las escuelas de San Carlos de Bariloche (Río Negro-Argentina), cuatro manuales, tres de editoriales argentinas (Kapelusz, Puerto de Palos y Estrada) y uno española (Santillana). De ellos dos corresponden a $3^{3}$, uno a $4^{\circ}$ y otro a $5^{\circ}$ grado.

Partimos de la hipótesis de que de las cuatro habilidades mencionadas (Mendoza, 1998), los manuales se centran en las de leer y escribir, descuidando la de hablar y, aún más, la de escuchar. Esto se correspondería con lo que históricamente viene 
sucediendo en distintos sistemas educativos, documentado en el caso de la enseñanza de la lengua francesa por Erard y Schneuwly, (2005:70) quienes afirman que durante mucho tiempo la enseñanza de lo oral tuvo como objetivo el mejoramiento de lo escrito, y el trabajo sobre el habla (le parler) de los alumnos se hacía en función de lo escrito. Mientras que el escuchar (I'écoute) permanecía muy marginado, más como medio que como objeto del trabajo escolar.

A continuación se presentarán los datos bibliográficos de cada obra y una breve descripción de la estructura de la misma. Después, el marco teórico que sustentará el análisis. Los datos que se obtengan permitirán evidenciar y sistematizar los procesos formativos impulsados desde los manuales mediante nociones discursivo-textuales, gramaticales y ejercicios. Todo ello permitirá determinar su incidencia en la formación de los alumnos.

\section{DesCriPCIÓN DEL CORPUS A ANALIZAR}

2.1. Sarceda, M. S. (1999). Historias en bicicleta 3. Lectura y escritura con áreas integrada. Buenos Aires: Kapelusz editora. (3o de nivel primario) (pp. 303)

Modalidad de trabajo en áreas integradas, siguiendo este orden: lengua, ciencias sociales, ciencias naturales, tecnología, formación ética y ciudadana, educación artística y matemática. Bajo la denominación de contenidos transversales se tratan aspectos relacionados con "valores". Consta de 11 capítulos, más un apartado final denominado "¡Recreo!" que incluye fragmentos de textos narrativos y poesías breves de autores literarios reconocidos.

Su prólogo está dirigido a los alumnos (niños de 8 años), por lo que es muy gráfico: incluye dibujos que complementan el sentido de las palabras, y los títulos de las diferentes secciones que componen el manual exhiben colores y grafías muy diversos y Ilamativos. Se trata de un prólogo muy breve que, para llegar a sus destinatarios, pone el acento en los elementos paratextuales.

\subsection{Ediciones Santillana (2006). Luna lunera 3. Bs. As., Santillana (pp. 295)}

La modalidad de trabajo que presenta es en áreas integradas. En la tapa de este manual aparece una indicación que da cuenta de que sus contenidos responden a los Núcleos de Aprendizaje Prioritarios (NAP). No tiene prólogo ni ninguna otra forma de presentación. Respecto del paratexto, su índice es muy sobrio, únicamente utiliza colores para diferencian las distintas áreas.

Los primeros 9 capítulos corresponden a las áreas de lengua, ciencias sociales y naturales, siendo más numerosos los contenidos de lengua; los 9 últimos, exclusivamente a matemática. Cuenta, además, con varios apartados: "Antología literaria", comprende una serie textos breves completos de autores contemporáneos argentinos (aunque abarcan diversos géneros literarios predominan los del orden del contar: fábulas y cuentos), siempre acompañados de preguntas acerca del sentido; "Fichas" y "Recortables", incluyen ejercicios más lúdicos que los del interior del manual que, una vez realizados, deben pegarse en la carpeta o cuaderno. 
2.3. Browarnik, G. et al. (2005). Puerto manual 4. Artesanal. Conectado, Bs. As., Puerto de Palos (pp. 543)

Los dos adjetivos que componen el título reflejan la esencia de este manual: Conectado, porque propone el estudio integrado de las áreas fundamentales: ciencias sociales, naturales, lengua, matemática e informática. Por lo que cada vez que un tema o ejercicio se relaciona con una área distinta de aquella en la que está ubicado, aparece el cartel de Conectado, indicando área, tema y página, lo que permite al docente dirigir las acciones de los alumnos a esa parte del libro.

Artesanal, por la variedad y tipo de ejercitación que, al menos en el área de Lengua, se propone: "El taller del escritor", "Cuarto con herramientas", "Con todas las letras", "Instructivos para recuperar amigos", etc.

No tiene prólogo, pero sí un índice muy detallado al comienzo del libro y un índice más sintético, precediendo a los capítulos de cada área. Desde lo paratextual, se atribuye un color diferente a cada área, color que también se refleja en el lomo del manual y permite una rápida ubicación. En el caso de lengua, los capítulos presentan títulos atractivos que Ilaman la atención y motivan la lectura. Contiene, además, "El paradigma de la conjugación de verbos regulares" y una breve Antología.

El área de lengua abarca desde el capítulo 14 al 23, y comprende 132 páginas.

2.4. Cano, M. F. et al. (2007). Lengua 5. Serie Entender-Segundo ciclo, Bs. As., Estrada (pp. 175)

Presenta contenidos exclusivos de lengua. El prólogo lleva por el título: "Para aprovechar este libro", y es una explicación gráfica de la estructura del manual para propiciar un uso eficaz del mismo. Mediante la reproducción de algunas páginas del manual y enunciados breves, se explican los abundantes elementos didácticos que se encontrarán en sus páginas.

Podemos afirmar que está dirigido tanto a alumnos (pre-adolescentes) como a docentes, La disposición gráfica de sus páginas recuerda la organización de la pantalla del ordenador, ya que en los márgenes hay recuadros (a modo de ventanas) con letra más chiquita y diferente color, que aportan la información más variada.

Son muchas las secciones que se repiten en cada capítulo y al final del libro se encuentra "El paradigma de la conjugación regular" y una antología denominada: "Leer por placer", que no incluye ningún tipo de ejercitación ni guía de lectura.

\section{MARCO teÓRICO}

Concebimos la Didáctica como un campo de intervención que se sitúa tanto en el campo científico como en el contexto social y político del momento. Además la entendemos "como una Área de conocimiento integradora y como una totalidad compuesta por elementos que coexisten y actúan independientemente" (Álvarez, 1998: 23). Esto nos permite afirmar que la didáctica de la lengua requiere de un trabajo interdisciplinar, ya que "es una disciplina que investiga la praxis escolar desde el punto de vista de la enseñanza y, a la vez, recibe de los campos disciplinares o 
áreas de conocimiento de referencia, entre los que se originan los paradigmas científicos, la presión social para que los objetos discursivos lleguen a la enseñanza, es decir, se divulguen" (Riestra, 2006: 16).

\subsection{El interaccionismo sociodiscursivo y la teoría de la actividad}

Para la enseñanza de la lengua, consideramos fundamental la concepción de lenguaje como acción (Bronckart, 1997) y su relación con la teoría de la actividad (Leontiev, 1983). Para este autor (en Riestra, 2000), la actividad humana no existe más que como forma de acción o finalidad de las acciones. La acción se produce como interacción y permite elaborar las capacidades mentales del individuo. Por lo tanto, se puede delimitar la acción como lo que hacemos en cualquier dominio operacional que ponemos de manifiesto en nuestro discurso. Por ello, este trabajo consiste en rastrear las acciones que los textos de las consignas de los manuales analizados proponen.

Cada actividad corresponde a una necesidad y está dirigida a un objeto capaz de satisfacer esa necesidad (está dirigida a una acción), por lo que en todo proceso de enseñanza-aprendizaje es necesario la delimitación de las acciones orientadas a una finalidad (tarea que deben realizar los profesores). Esas acciones concretas constituyen el contenido de las actividades y plantea la cuestión de las relaciones internas que las vinculan.

El interaccionismo sociodiscursivo (Bronckart, 1977) considera a los signos, así como a los textos en los cuales se organizan, como productos de la interacción social. "Los humanos somos tales por la actividad de lenguaje, que se organiza en discursos y produce textos para mediar las otras actividades sociales" (en Riestra, 2006: 23). También considera la actividad de lenguaje como acción humana adquirida en los intercambios de prácticas verbales realizadas entre los agentes humanos, prácticas que a la vez elaboran las capacidades mentales y la conciencia de los mismos agentes. Por tanto, "los textos son mediadores de la acción y se producen en una formación social determinada (contexto), de acuerdo con modelos existentes o géneros de textos" (en Riestra, ídem: 18) reconocidos por los agentes, por los hablantes. Coincidimos con Riestra (2008) en que la didáctica de la lengua materna debe proporcionar a los alumnos un dominio real y práctico de la lengua en uso en su comunidad. Es decir, ocuparse de la enseñanza del leer y del escribir en la articulación entre el pensamiento y el lenguaje. Por lo tanto, la finalidad concreta de la educación será lograr que los alumnos desarrollen sus capacidades discursivas con habilidades específicas en las actividades de leer y de escribir con autonomía aceptable. En consecuencia, es evidente nuestra adhesión a un enfoque comunicativo de la lengua que va a ser el que organice este trabajo. Para ello retomamos la idea de que la acción de lenguaje produce textos que pueden ser orales o escritos. En el orden de la oralidad, la situación comunicativa de los textos domina el contexto de producción, mientras que en la escritura es el contexto (intra e intertextual) el que domina la situación o la suple. Por estar situado en una práctica comunicativa y social concreta, todo texto tiene una composición genérica, un principio organizador que nos permite clasificarlos en géneros textuales. 


\subsection{Las capacidades lingüísticas}

Para internarnos en esta problemática es necesario buscar aproximaciones conceptuales y terminológicas entre los diferentes marcos teóricos que se ocupan del tema.

En este trabajo, nos basamos en los desarrollos del Interaccionismo sociodiscursivo cuando sostiene que "la noción de capacidad lingüística (Dolz, Pasquier y Bronckart, 1993) se refiere a las aptitudes que el alumno requiere para la producción de un género [textual] en una situación de interacción determinada: adaptarse a las características del contexto y del referente (capacidades de acción), movilizar modelos discursivos (capacidades discursivas) y dominar las operaciones psicolingüísticas y las unidades lingüísticas (capacidades lingüístico-discursivas)" (en Dolz y Schneuwly, 1997: 85). Esta cita nos muestra un panorama mucho más complejo y amplio de lo que en un primer momento habíamos sospechado: el lenguaje y su dimensión psicológica, y la posibilidad de intervenir en las operaciones psicológicas vinculadas con el lenguaje para poder propiciar su desarrollo en cada alumno.

Los humanos contamos con capacidades lingüísticas para "las actividades de expresión escrita y oral" (Dolz y Schneuwly, 1997), es decir, para la actividad de escribir y la actividad de hablar.

Consideramos que las dos actividades fundamentales que se ejercitan en el ámbito escolar son la actividad de lectura (comprensión de textos leídos) y la actividad de escritura (capacidad para elaborar textos escritos autónomos). Se enseñan y desarrollan "las capacidades discursivas con habilidades específicas en las actividades de leer y escribir" (Riestra, 2008). El enfoque comunicativo del lenguaje nos Ileva a entender el lenguaje como acción (individual) que se inscribe en una actividad colectiva, por lo tanto leer y escribir se desarrollan actuando en situaciones de comunicación diversas y concretas que la escuela debe propiciar y la didáctica de la lengua y la literatura deben investigar y sistematizar.

Por lo mismo, las habilidades de hablar y escuchar implican "capacidades discursivas con habilidades específicas en las actividades de hablar y escuchar", entendida esta última como "comprensión oral". Entonces, la habilidad de hablar sería la capacidad de expresarse oralmente (de elaborar textos orales autónomos) propia del orden de lo oral. Mientras que la habilidad de escuchar (que presenta una dificultad mayor en el momento de definir su naturaleza) Schneuwly (refiriéndose siempre al ámbito escolar) la ubica entre las actividades lingüísticas de comprensión y expresión oral, como contrapunto de las del escrito: "las actividades lingüísticas de comprensión y expresión oral, como contrapunto de las del escrito, están llamadas a convertirse en el centro de las preocupaciones..." (Dolz y Schneuwly 1997: 92).

Nos parece muy acertada la denominación "comprensión oral" para referirse a la habilidad de escuchar. Por lo tanto, en este trabajo la habilidad de escuchar (Erard y Schneuwly, 2005) la relacionaremos con la comprensión que los alumnos logran de los textos, tanto orales como escritos, es decir, con las actividades de leer (para los textos escritos) y de escuchar (si se trata de textos orales).

Nos resultará útil para el análisis la categoría denominada "actividades gramaticales". La tomamos de la distinción que Dolz y Schneuwly (1997) establecieron al refe- 
rirse a "las actividades de expresión escrita y oral" (actividad de escribir y actividad de hablar) frente a lo que denominan las "actividades gramaticales". Consideramos que está relacionada con las capacidades lingüístico-discursivas de los hablantes.

En síntesis, el Interaccionismo sociodiscursivo nos ofrece herramientas para analizar los procesos de formación de las capacidades lingüísticas de los alumnos que tienen lugar en la escuela, generalmente, mediante el trabajo con los manuales de lengua. Los alumnos cuentan con capacidades lingüístico-discursivas adquiridas socialmente en el uso del lenguaje en su comunidad, que la escuela debe desarroIlar y ampliar (favorecer su dominio en situaciones más complejas, para así desarrollar un comportamiento lingüístico consciente y voluntario que favorezca la autorregulación). Esto se logra mediante la enseñanza de los géneros textuales, ya que son el único modo de dominar y actuar en situaciones concretas de comunicación, dado que son el "principal instrumento de interacción social", "un elemento constitutivo de la situación: sin novela, por ejemplo, no hay lectura ni escritura de novela; sin lugar a dudas, ésta es una de las particularidades del funcionamiento lingüístico en general..." (Dolz y Schneuwly, 1997: 84). El desarrollo de las capacidades (habilidades) lingüístico-discursivas implica operaciones psico-lingüísticas así como la elaboración de unidades lingüísticas (o elaboración del texto). Estas capacidades se interrelacionan, las capacidades discursivas requieren de capacidades lingüísticas y comunicativas. Podemos distinguir tres niveles de operaciones lingüísticas para el dominio de un género, o sea, del lenguaje: el nivel de las capacidades discursivas que requieren de capacidades lingüísticas y comunicativas; el nivel de las capacidades de acción, donde hay que conocer el contexto social y poder representarse la contextualización de un género para saber qué decisiones tomar al elaborar un texto; el nivel de las capacidades discursivas, que supone conocer y ser conscientes del conocimiento de modelos discursivos, de la estructura discursiva del texto; y, por último, el nivel de las capacidades lingüístico-discursivas, sobre la capacidad de elección de las unidades lingüísticas o de elaboración del texto (conocimiento de la lengua). Esta es la concepción del aprendizaje que nos aporta el interacionismo sociodiscursivo, como la reorganización de las capacidades lingüísticas dominantes de los alumnos.

En este trabajo, nos disponemos a analizar la presencia, en los manuales, de las cuatro habilidades. Además, una vez fundamentada la necesidad de explicitar la distinción entre lectura y escritura como dos actividades diferenciadas (aunque relacionadas) en su dominio, ya que requieren de acciones diferentes, las identificaremos para observar cómo son presentadas. Lo mismo haremos con que las actividades de hablar y comprensión oral, así como con las actividades gramaticales. Para ello seguiremos el siguiente esquema de análisis:

Capacidades lingüísticas con habilidades en las actividades de:

1.1. Actividades de expresión oral (Dolz y Schneuwly, 1997). Actividades lingüísticas de comprensión y expresión oral (Schneuwly, 1997).

1.1.1. Actividad de comprensión oral (Schneuwly, 1997). Recepción oral (Dolz y Gagnon, 2008). Escuchar.

1.1.2. Actividades de hablar (Dolz y Schneuwly, 1997). Elaboración de textos orales. Hablar. 
1.2. Actividades de expresión escrita (Dolz y Schneuwly, 1997).

1.2.1. Actividad de lectura (Riestra, 1999, 2008). Comprensión de textos escritos. Leer.

1.2.2. Actividades de escritura (Riestra, 1999, 2008). Elaboración de textos escritos. Escribir.

1.3. Actividades gramaticales (Dolz y Schneuwly, 1997).

\section{Metodología de ANÁlisis}

La lectura de los manuales en general y, particularmente, de los textos de las consignas posibilitó el estudio pretendido. La organización de los dados obtenidos fue posible gracias a la elaboración de diversos cuadros que permitieron clasificar los contenidos presentes en los manuales, según las nociones desarrolladas en el marco teórico.

Se confeccionaron cuatro cuadros similares, uno por cada manual, que constituyen una apretada síntesis de los contenidos. La finalidad fue mostrar información acerca de los géneros textuales, las nociones teóricas y los ejercicios. Además, las nociones teóricas se clasificaron atendiendo a la actividad a la que se refieren: de expresión escrita (leer y escribir), de expresión oral (hablar y comprensión oral) o gramaticales. Respecto de las nociones textuales y discursivas, se indica cómo son transmitidas desde el uso (conceptos cotidianos) o desde la teoría (conceptos científicos). De la misma forma se procedió con las actividades gramaticales, se clasificaron según la modalidad en que son transmitidas desde el uso (conocimientos cotidianos que los alumnos adquirieron fuera de la escuela) o desde la normativa.

\subsection{Nociones vehiculizadas en los manuales}

En este apartado se procederá al análisis de las nociones discursivo-textuales y gramaticales, así como de los ejercicios propuestos a los alumnos para el aprendizaje de los contenidos y el desarrollo de las habilidades de hablar, escuchar, leer y escribir.

4.1.1. Sarceda, M. S. (1998). Historias en bicicleta 3. Lectura y escritura con áreas integradas. Buenos Aires, Kapelusz editora. (3o de nivel primario) (pp. 303)

Las nociones gramaticales predominan sobre las discursivo-textuales, por ello la mayor cantidad de ejercicios corresponde a actividades gramaticales. La modalidad de la ejercitación se repite constantemente: separar, subrayar, completar, ordenar, marcar, armar oraciones, hacer listados, etc. (ver anexo: cuadro 1). La metodología para la enseñanza de los contenidos gramaticales consiste en partir de los conceptos cotidianos (registrados como "uso" en los cuadros del anexo) para, a continuación, presentar las nociones teóricas. El mismo procedimiento se observa en lo que se refiere a nociones discursivo-textuales (ver cuadro 1). Pasamos a describir algunos ejemplos de este tipo de ejercicios: realizar un listado de objetos del aula, para después explicar la categoría gramatical "sustantivo". Previa a toda explicación, la noción de singular y plural aparece relacionada con la clasificación de varios sus- 
tantivos en dos listados denominados: "Uno" y "Más de uno". La construcción morfológica de los plurales se presenta (comenzando por los casos más sencillos) mediante dos listados de palabras, lo que implica ausencia total de la noción teórica de concordancia. La noción de género gramatical es planteada de la misma forma, realización de dos listados denominados: "El" y "La", sin explicaciones teóricas ni referencias a la concordancia, pero con clara progresión en función de la dificultad ortográfica de los sustantivos dados: de las formas más sencillas a las más complicadas. Avanzando en la lectura del manual, al introducir la categoría de adjetivo vuelven a aparecer ejercicios en torno a la noción de concordancia (sin emplear este término técnico). El procedimiento sigue siendo el mismo, se parten de un texto y del concepto cotidiano de "compañía" y se pide a los alumnos que busquen las palabras que acompañan a determinados sustantivos. También encontramos los habituales ejercicios con la modalidad de corrección del error: dado un texto con errores (de concordancia), se solicita a los alumnos su corrección.

Respecto de las nociones textuales, se plantean ejercicios que se corresponden tanto a actividades de lectura como de escritura. El procedimiento para Ilevar a cabo actividades de lectura que más se repite es el de preguntas sobre el texto, mientras que las tareas propuestas para las actividades de escritura presentan mayor variedad. El análisis de los textos de las consignas denota que en los ejercicios tendientes al desarrollo de las habilidades discursivas de leer no se tienen en cuenta aspectos de la coherencia pragmática, faltan datos relacionados con la situación comunicativa de texto que contribuirían a la comprensión del mismo. Sin embargo, un aspecto positivo es que las actividades de expresión escrita se basan en los textos leídos, por ejemplo, elaboración de un texto cambiando de género textual del propuesto para las actividades de lectura: "Ahora se trata de contar la fábula, siguiendo la historieta, cuadro por cuadro. Tenés que escribir lo que corresponde a cada cuadro, en los renglones en blanco." (p. 173); o continuar un relato dado: "Se trata de modificar la narración. Pueden cambiar el inicio, introducir personajes..." (p. 151). Esta decisión de organizar las actividades de escritura en torno a un modelo viene a subsanar en parte la falta de contexto que según Dolz (et. al., 1993) afecta a las capacidades de acción de los hablantes. Hay algunos intentos de integrar los conocimientos gramaticales con la actividad de escritura: "Busquen más palabras con bl y br para armar otros trabalenguas" (p. 248) ${ }^{1}$.

En cuanto a las actividades de expresión oral, hemos tenido que rastrearlas por todo el manual, dado que los ejemplos más significativo se encuentran las áreas de Ciencias Naturales y Sociales. Creemos conveniente mencionarlas porque los textos de estas consignas destacan por la precisión en la formulación de las tareas y constituyen una muestra del trabajo en áreas integradas que el manual propone. Encontramos casos en los que las actividades de comprensión oral (escuchar) se relacionan explícitamente con la actividad de lectura: Leer a los compañeros la historieta creada y escuchar la lectura del resto de las historietas; y con la actividad de lectura y las

1. Se respetan en todos los casos las formas textuales de los manuales, que siguen la norma argentina en el uso de las formas verbales y en otras expresiones propias de esos ámbitos hispanoamericanos. 
que hemos denominado "Otras actividades" ya que se propone la musicalización de un texto: acompañar con música la lectura de la leyenda dada en el manual. Hay que destacar que son más numerosos los casos en los que la consigna solicita que en grupos se arme una historia (cuento), pero no se aclara si han de escribirla, sin han de exponerla oralmente; sospechamos que con esta modalidad se pretende incentivar las habilidades de hablar y escuchar y así han sido registradas en el cuadro 1).

En síntesis, predominan las actividades de lectura y los ejercicios que basándose en un texto dado persiguen el aprendizaje de nociones gramaticales. Las propuestas de elaboración de textos autónomos (escritura en el cuaderno, pues el manual no contempla espacio suficiente) son escasas y, en general, se refieren a los géneros textuales más accesibles a niños de ese nivel: cuento, historieta y poema breve.

Nos Ilama la atención la cantidad de información extra solicitada a alumnos de nivel primario. No sabemos si se trata de tarea a realizar en la casa o simplemente de una sugerencia, porque no aparecen pautas que guíen su realización.

\subsubsection{Ediciones Santillana (2006). Luna lunera 3. Bs. As., Santillana (pp. 295)}

Son muchos y muy sistematizados los contenidos gramaticales que presenta este manual, prueba de ello es que siempre, al final de cada capítulo, se trata un aspecto ortográfico. Las nociones gramaticales (normativa) son presentadas tanto desde conceptos cotidianos como técnicos, aunque debemos aclarar que estos últimos están solamente expuestos en un recuadro, por lo que consideramos que no son el objeto primero de enseñanza, (estarían incluidos en un proyecto a largo plazo, cuyo fin sería que los alumnos los incorporen paulatinamente). Además de los clásicos ejercicios gramaticales, propone otros que acercan al alumno a la existencia de géneros textuales concretos, por lo que constituyen actividades gramaticales: Resolver enigmas basados en la acentuación de las palabras o escribir un texto disparatado asociando tríos de palabras que comiencen con HIE, HUE y HUM; usar la coma para separar los elementos de una enumeración. De este modo se logra la integración entre las actividades gramaticales y las actividades de escritura.

Las tareas propuestas para el desarrollo de las habilidades de expresión escrita (leer y escribir) son muy numerosas. Podemos afirmar que las actividades de lectura propuestas en este manual son más variadas que las encontradas en el anteriormente analizado: Leer los refranes y explicar en qué situaciones fueron escuchados; marcar con una cruz y explicar oralmente el porqué... Estos ejemplos permiten ver cómo el desarrollo de la habilidad de leer se vincula a las actividades de expresión oral (hablar-escuchar) y no tanto a la habilidad de escribir. Creemos que la razón de ello reside en la dificultad que la escritura presenta en los primeros años de escolaridad.

Las actividades de escritura también son muy numerosas y están muy bien organizadas y pautadas, integrando aspectos discursivos y gramaticales: "Releé la carta de Santi y respondela como si fueras Angelita. En la carta incluí: dos preguntas; un pedido; una expresión de..." (p. 45); escribir las observaciones sobre el sonido de la " $g$ " que se realizaron oralmente. El análisis de estas consignas muestran que el foco recae en la función comunicativa del lenguaje, incorporando, al mismo tiempo, el dominio de algunos procedimientos ortográficos, así como el trabajo en áreas inte- 
gradas: Elegir una de las provincias y escribir una adivinanza en forma de verso. Leer las adivinanzas y descubrir a qué provincia se refieren, ubicarla en el mapa. Además se integra el trabajo de diversas habilidades: escribir, hablar, escuchar y "otras": plano gráfico del mapa. Otro ejemplo: la reproducción de cuadro de Pedro Fígari "Hacia la noche" da lugar a una actividad de escritura: un diálogo entre la Luna, el árbol y el caballo: "¿Qué se dirían la Luna, el árbol y el caballo si pudieran hablar? Inventá ese diálogo imaginario y escribilo en tu cuaderno" (p.135).

Las actividades de expresión oral constituyen los ejemplos más claros de coherencia pragmática en las tareas solicitadas a los alumnos, porque implican el desarrollado de las cinco habilidades: Marcar con una cruz la respuesta correcta (texto leído) y explicar oralmente por qué la elegís; elegir un refrán y dramatizar una situación en la que se pueda usar (escuchar queda implícito); emplear los adjetivos de la cadena para escribir adivinanzas que brinden pistas sobre algunos compañeros de clase (escribir, gramática y hablar (escuchar queda implícito); pedir a los abuelos que les canten una canción sobre la luna y copiarla en el cuaderno (escuchar y escribir; hablar queda implícito, ya que se supone que en el aula se expondrá (cantará) lo copiado); descubrir las palabras escondidas en el dibujo, leerlas en voz alta y señalar en qué casos la "g" suena suave y en cuáles fuerte (otras habilidades, leer, hablar, escuchar y gramática).

4.1.3. Browarnik, G. et al. (2005). Puerto manual 4. Artesanal. Conectado, Bs. As., Puerto de Palos. (pp. 543)

En este manual, el número de nociones discursivo-textuales presentadas es muy alto, pero todavía se mantiene el predominio de las nociones gramaticales. Sin embargo, podría decirse que las actividades de escritura son el principal objeto de enseñanza (sin desestimar el ejercicio de otras habilidades), ya que podemos afirmar que, comparándolo con otros manuales, es menor el número de ejercicios centrados exclusivamente en aspectos gramaticales. En Puerto de Palos encontramos actividades gramaticales, porque la ejercitación de estos aspectos alcanza una integración con las actividades de escritura mayor a lo, hasta ahora, observado: "Escriban una leyenda que incluya los siguientes datos, [...] Incluyan un diálogo entre los protagonistas respetando el uso de la raya de diálogo. Antes de pasar la leyenda a la carpeta, pónganle un título. Revisen que todos los verbos se encuentren en pasado..." (p. 187). Lo mismo sucede con aspectos morfológicos: "Inventen palabras que combinen los prefijos y sufijos anteriores con las palabras de la segunda lista y luego expliquen su significado, por ejemplo: autotarea" (p. 240).

En cuanto a las actividades de expresión escrita es el manual que más se ocupa de la situación comunicativa de los textos leídos y que mejor recrea el contexto de los que han de ser elaborados por los alumnos. Respecto de la actividad de lectura, los repetidos ejercicios de responder preguntas sobre el sentido del texto alternan y se complementan con otros que llevan a los alumnos a reflexionar sobre los elementos del contexto de producción. Por ejemplo, el modelo de carta presentado aparece como obra de las autoras del manual y las preguntas acerca del texto se refieren a la finalidad, destinatarios, etc. Otros ejemplos: Responder preguntas sobre el destinatario de los textos; comparar, entre todos, distintos textos instructivos. 
Propuestas similares encontramos en las consignas de las actividades de escritura: "Trabajen en parejas. Imaginen una situación en la que uno es un personaje y el otro le escribe una carta. [...] El que recibe la carta tiene que responderla..." (p. 171). La consigna, primero, da pautas sobre aspectos textuales: destinatario, remitente y la relación entre ambos; lenguaje adecuado a la situación; y, después, sobre aspectos normativos: ortografía y signos de puntuación y entonación.

Este manual presenta un trabajo sistematizado de las actividades de expresión oral en todas las áreas, no sólo en Lengua, a través del apartado "Educación en valores", $^{\prime \prime}$ con consignas para armar debates en tono a diversos temas, por ejemplo, respeto por el otro, por el turno de intervención. Destacamos este tema por estar relacionado con las habilidades que nos ocupan.

Otra novedad respecto de lo que venimos observando en los manuales analizados es que las consignas que se refieren a actividades (de expresión escrita y gramaticales) incorporan tanto de forma implícita como explícita el desarrollo de habilidades de expresión oral: Leer en voz alta dos notas con el mismo texto, pero diferentes signos de puntuación: interrogación y exclamación. La tarea propuesta implica habilidades de leer; de escribir teniendo presente la normativa para realizar los cambios indicados; de hablar y de escuchar. Por tratarse de un ejercicio de entonación, la habilidad de escuchar se torna fundamental aunque no esté explicitada. Otros ejemplos: "Piensen y discutan entre todos: ¿qué tienen en común las palabras resaltadas?, ¿qué parte de la palabra se repite en cada caso?" (p.174); leer en voz alta las palabras e identificar la sílaba tónica; discutir si las oraciones son correctas y por qué (adverbios).

4.1.4. Cano, M. F. et al. (2007). Lengua 5. Serie Entender-Segundo ciclo, Bs. As., Estrada (pp. 175)

Creemos que, por tratarse de un manual para el segundo ciclo, es el que mayor cantidad de nociones y ejercicios presenta. Pero si bien se trata del manual que más contenidos teóricos (tanto discursivo-textuales como gramaticales) aporta y el que más ejercitación propone, también es cierto que lo hace de forma escindida, no propone el trabajo integrado de las distintas habilidades y sus ejercicios no alcanzan el estatus de actividades en el sentido desarrollado en este trabajo. Esto es evidente al analizar las secciones en las que se organizan sus capítulos: Las tareas propuestas en "Palabras orales" se refieren a la comprensión del texto leído (actividad de lectura) y nunca se relacionan con las actividades de expresión oral (ver cuadro 4). Se plantean preguntas sobre el texto sin explicitar de qué forma (soporte, habilidad, por escrito, oral, mentalmente, etc.) han de responderlas los alumnos.

En general, las consignas son muy largas, mezclando acciones que apuntan a diferentes actividades sin un criterio que organice la tarea que han de realizar los alumnos, como si el fin último fuera abarcar todos los contenidos vistos en el capítulo. Esto puede observase en las consignas de la sección "Trabajo práctico": "Relean completo el cuento [...] Escriban en sus carpetas qué sucede en la situación inicial, el conflicto y la resolución. Narren la explicación del caso. Contesten a las siguientes preguntas y analicen sintácticamente sus respuestas..." (p. 129). 
Los siguientes ejemplos ilustran que no se trata de actividades gramaticales, sino de simples ejercicios: "Digan en qué número y persona [...] Digan en qué modos, tiempos, números y personas están conjugados los núcleos verbales y por qué se usan esos tiempos." (p. 85).

Pese a lo expuesto, hay algunas consignas que constituyen actividades de expresión oral a la vez que trabajan cuestiones discursivo-textuales: Realizar entrevistas al personal de la escuela. Escucharlas y comentar si las preguntas fueron adecuadas y si se logró la información pretendida. Otro ejemplo de actividad es el trabajo sobre el ritmo y la rima en poesía: Leer los poemas, marcando el ritmo con el pie, hacer cada sílaba con un golpe. En grupo, contar las estrofas y versos de los poemas leídos.

\section{ANÁlisis DE LOS DATOS RELEVADOS}

Todos los manuales analizados se organizan en torno a la noción de género textual (aunque ninguno utilice esta terminología); hay coincidencia en los géneros tratados: cuento (con subgéneros: policial, de ficción, etc.), historieta, noticia, etc. Los géneros se repiten en los distintos grados (y grupos editoriales) como estrategia didáctica para que los alumnos los aprendan gradualmente. En algunos manuales, en un mismo capítulo encontramos dos géneros textuales distintos, en estos casos siempre, uno de ellos es un cuento en el que recae la actividad de lectura mientras que el otro género permite la enseñanza (ejercitación) de nociones textuales o discursivas. En todos los casos los textos son abordados mediante las dos actividades que nuestro marco teórico diferencia: actividad de lectura y actividad de escritura, comenzando siempre por la de lectura. Ésta ocupa mayor número de páginas, pero sus consignas son menos elaboradas, proponiendo ejercicios muy similares. Como se repiten las mismas ejercitaciones en todos los capítulos y en cada manual analizado, es interesante observar qué manuales plantean variantes. Por ejemplo, el tipo de ejercitación más común es: Responder una guía de preguntas sobre el sentido del texto o realizar ejercicios (completar, marcar, unir) que reflejen la comprensión del texto. En los manuales de 4 y 5 grado, además de esto, encontramos otras propuestas: Preguntas sobre la voz que enuncia y el destinatario, y preguntas sobre elementos del paratexto: comillas, cursiva, paréntesis. Además, queremos destacar la interesante labor del equipo de la editorial Puerto de Palos que detalla la situación comunicativa de algunos géneros textual presentados, concretamente al proponer como modelo de carta, una misiva escrita por las autoras del manual: "Eugenia y Victoria son las autoras de la parte de Lengua de este libro y las remitentes de la carta. ¿Quiénes son los destinatarios?" (p. 170).

En general las actividades de escritura son muy elaboradas, sobre todo en manuales de los niveles superiores (4 y 5 grado). Incluyen y proponen la realización de varias acciones que permitirán a los alumnos elaborar un texto completo, planificado y con sentido, es decir, autónomo. El manual de la editorial Estrada contiene numerosos ejemplos, releer el texto dado (del género teatro) y reescribir una escena (concreta) incluyendo acotaciones sobre la actitud del personaje y sus gestos: "Relean la obra prestando atención a lo que se cuenta que pasó en ese momento. Luego, escriban esa escena. Los personajes deberían ser la Sirenita y el pescador, y la escena debería transcurrir en un muelle. Recuerden incluir acotaciones sobre cómo dicen las frases y los gestos que hacen." (p. 108). Escribir una nueva versión del cuento leído, cambiando 
de narrador, narrándolo desde el punto de vista del loro: "Con lo que saben hasta acá escriban una nueva versión del cuento, narrada por el personaje del loro (después de todo, es el único personaje que sabe quién le dio el mensaje). Recuerden incluir cómo son el resto de los personajes, el detective y Lucas, según la mirada del pájaro que habla." (p. 121). Un tercer ejemplo, "Escriban una autobiografía. Para ordenarse, empiecen escribiendo una lista de los hechos más importantes que van a relatar. Luego, a la izquierda, coloque los años o las fechas cuanto sucedieron esos hechos. Así, esta cronología los guiará mientras escriben sus autobiografías." (p. 81).

La editorial Puerto de Palos, también, tiene buenos ejemplos de consignas bien pautadas que proporcionan a los alumnos una idea muy completa de la situación comunicativa del texto que van a escribir: "Elijan a alguna persona conocida y escriban su biografía. [...] a) Diseñen un cuestionario para saber cómo fue y es su vida [...] b) Recolecten toda la información, ordénenla cronológicamente y no olviden usar los conectores para que el texto tenga sentido." (p. 205). Otro ejemplo: "Inventen entre los dos una publicidad para vender "almohadernos". Tengan en cuenta los siguientes pautas: a) Imaginen cómo sería un "almohaderno", dibújenlo de modo que resulte atractivo para los compradores. b) Elijan dos o tres cualidades del producto que quieran resaltar y escriban un texto con ellas. c) Piensen cómo van a convencer al público de las ventajas de tener un "almohaderno". d) Diseñen el aviso, ubiquen los textos y los dibujos. ¿Cómo les quedó?" (p. 209). Las consignas de este manual están presentadas con más claridad que las del anteriormente comentado, ya que las acciones propuestas se especifican (incluso desde el paratexto) y aparecen diferenciadas, unas de otras. Además, la formulación de las consignas es más precisa, porque emplea el imperativo como forma verbal para expresar órdenes. Contrariamente, en el manual de Estrada hay consignas construidas con verbos modales y en condicional (deberían ser), formas verbales que sugieren, no ordenan.

También, en los manuales de niveles inferiores (3 grado Santillana) encontramos buenos ejemplos de formulación de consigna, ya que se crea una situación comunicativa tan concreta como el ámbito escolar permite: "Releé la carta de Santi y respondela como si fueras Angelita. En la carta incluí: dos preguntas; un pedido; una exclamación de alegría por la invitación y una expresión de duda." (p. 45). Incluimos este ejemplo porque muestra del aspecto que vamos a desarrollar a continuación.

Con respecto a las actividades gramaticales, considero que son muy pocas las encontradas en los manuales analizados. Es cierto que hay muchos ejercicios gramaticales, pero éstos no constituyen una actividad, entendida en el sentido atribuido en este trabajo. Por tanto, los manuales presentan nociones gramaticales y ejercicios sobre ellas, que rara vez constituyen una actividad tal como lo desarrollara Leontiev (1983). Tomamos como ejemplo el manual de Estrada, porque es el que más páginas dedica a las nociones gramaticales; contiene abundantes ejercicios que no constituyen una actividad en sí mismos, ya que no persiguen la elaboración de un texto, simplemente presuponen que mediante el procedimiento de repetición los alumnos aprenderán las nociones gramaticales. En este tipo de ejercicios el uso comunicativo del lenguaje queda relegado, por lo que el objeto de aprendizaje pretendido pocas veces se alcanza. Sin embargo, también propone actividades de escritura que supeditan la normativa a la función comunicativa del lenguaje. 
De todos los modos, hemos encontrado actividades de lectura en las que alguna de las acciones propuestas persigue el aprendizaje de cuestiones gramaticales y creemos que son más numerosos en los manuales de años inferiores, pero no podemos afirmarlo por la muestra limitada que hemos tomamos. En Luna lunera 3 de SantiIlana encontramos propuestas como las siguientes: Responder una carta dada, utilizando verbos en los tres tiempos; "Imaginá qué harán los hombres del futuro que vivirán en colonias espaciales. Escribí en el cuaderno algunas de las acciones [...] utilizando verbos en tiempo futuro." (p. 132) y "Escribí un texto que cuente lo que pasó en las viñetas. Utilizá mayúscula; sangría; punto y seguido, y punto y aparte, según corresponda. Organizalo en dos párrafos. Ponele un título." (p. 31).

Dejamos para el final el comentario de algunos casos encontrados en el manual de la editorial Kapelusz, que muestran consignas que probablemente no logren su finalidad. Nos animamos a afirmar que los alumnos no podrán realizar la actividad de escritura que a continuación se transcribe, por tratarse de una consigna muy abierta y poco pautada: "Escribí algo sobre vos y tus amigos. Si querés, también podés dibujar" (p. 153). Un caso similar lo constituye una consigna en la que no se discriminan las actividades de lectura y escritura: "Reúnanse en grupos pequeños, comenten y piensen. Luego escriban: ¿Cómo resolverían la primera propuesta? ¿Qué final pueden imaginar para la segunda? Como ven, a Pepino le gustan las aventuras. Acepten la invitación y escriban una historia con este personaje. Después la leen a los compañeros." (p. 245). Comienza como una actividad de lectura (preguntas sobre el sentido del texto) y termina proponiendo una actividad de escritura poco pautada. Consideramos que, mediante una consigna muy extensa, se pretende que alumnos de 8 años realicen demasiadas acciones (implícitas, la mayoría). El texto deja ver que la formulación de la consigna encierra muchos supuestos, supone que los alumnos ya saben lo que tienen que hacer para lograr la finalidad de la actividad.

En el manual de Puerto de Palos, algunos aspectos normativos y/o fonológicos (puntuación) son trabajados en grupo y, por lo tanto, en el orden de la oralidad, cuando propone a los alumnos que lean en voz alta dos notas con el mismo texto, pero diferentes signos (interrogación, exclamación): "Lean las notas en voz alta. ¿Cómo suena cada una?" (p. 155). Se trata de una tarea a realizar en el aula que permite trabajar tanto las habilidades de hablar como de escuchar. Este ejemplo introduce un nuevo aspecto de nuestro análisis las actividades de expresión oral que ocupan pocas páginas en los manuales analizados. Por ejemplo, la editorial Estrada incluye un apartado denominado: "Palabras orales", que en el prólogo es presentado como "actividades que se responden hablando", pero su contenido son meras preguntas que si bien guían la lectura que los alumnos realizan, los ayuda a interpretar el texto y a relacionar información (intra y extratextual), no incluyen ningún procedimiento (ni debate, ni puesta en común, ni anotación de las respuestas en el cuaderno) que a los alumnos les permita desarrollar las habilidades de hablar y escuchar. Consideramos que la consigna no está formulada con precisión, ya que no establece ninguna actividad concreta, ni oral ni escrita, por lo que sospechamos que, posiblemente, los alumnos no sepan qué tienen que hacer. En el mismo manual encontramos: "Palabras escritas", que aglutina ejercicios que los alumnos han de 
realizar en sus cuadernos, aunque no siempre se trata de actividades de escritura, a veces son meros ejercicios sobre aspectos gramaticales.

Nos arriesgamos a afirmar que propuestas para trabajar las habilidades de hablar y escuchar de manera sistemática pueden encontrase en el manual de Puerto de Palos, porque todos los capítulos tiene la sección "Educación en valores", donde se plantean, mediante la modalidad de trabajo grupal, tareas de integración entre las distintas áreas. A pesar de que en ningún momento se explicita este objetivo (el desarrollo de estas habilidades) y aunque en la consigna no aparezcan rasgos que denoten el trabajo con el cuerpo, con la voz, ni la disposición para escuchar al compañero, interpretamos que de realizarse en el aula propiciarían el desarrollo de las mencionadas habilidades. El único caso que, dada la temática, trata estos aspectos es el siguiente: "Educación en valores. [...] Comenten entre todos: ¿qué pasaría en el aula si todos hablaran al mismo tiempo y nadie respetara así su turno para intervenir en la conversación? ¿Cuál sería la manera más apropiada de lograr una buena comunicación en el aula?" (p. 159). Consideramos que el apartado "Educación en valores" es la actividad con más posibilidades de trabajar las habilidades mencionadas.

En el manual de Santillana, en una ocasión, se plantea el tema de los valores, pero no sistemáticamente, sólo cuando la temática del capítulo lo propicia.

Volviendo a los géneros textuales tal como son tratados en los manuales, el teatro es el que propicia más (y casi exclusivamente) situaciones en las que verdaderamente se enfocan estas habilidades. En Puerto de Palos encontramos: "En equipos organicen la representación de la obra que acaban de leer." (p. 194). En Estrada: "Si se animan, pueden representar Explicaciones de la Sirenita o alguno de los textos que hayan escrito ustedes." (p. 109).

Los casos más numerosos, detectados en todos los manuales, son los que proponen compartir una producción escrita por los alumnos: "Escriban una historieta. Para ello, respeten las siguientes indicaciones: [...] e) Organicen en el aula una expo-humorística en donde muestren todos sus trabajos." (Puerto de Palos, p. 167). En este caso, se trataría más de una muestra gráfica que oral. Veamos otros ejemplos: "Elegí tres animales que aparezcan en el cuaderno e inventá colmos sobre ellos. Luego, compartilos con tus compañeros." (Santillana, p. 63). En ambos casos el desarrollo de las habilidades de hablar y escuchar sería la consecuencia de una actividad de escritura; la finalidad de ejercitar la oralidad quedaría implícita, ya que la consigna no explicita cómo hacerlo.

Otra generalidad observada es que los manuales introducen los contenidos teóricos desde el conocimiento cotidiano, en un intento por recuperar los saberes (sobre géneros textuales, empleo de los verbos, etc.) que los alumnos poseen, que aprendieron mediante el uso de la lengua. Consideramos que es una decisión didáctica, ya que a partir de lo que los alumnos conocen, es posible el aprendizaje. Esto es muy evidente en los manuales de niveles inferiores y persiste en niveles más elevados. En el manual de Santillana son muy numerosos los aspectos morfológicas y ortográficas y siempre se presentan en estos términos: "Palabras que describen", "Pedacitos de palabras", "Para decir lo mismo y lo contrario" etc. Las cuestiones técnicas, cuando aparecen, quedan relegadas a un pequeño recuadro en un rincón de la página. 
Esta forma de didactizar la noción teórica hace que la que sería la tercera habilidad a desarrollar en la educación obligatoria (siguiendo a Briz, 1998), la reflexión sobre la lengua y el análisis del texto escrito, apenas se vea reflejada en los manuales analizados. Suponemos que se abordará en niveles superiores, posiblemente en el nivel de enseñanza media. En el caso de la editorial Estrada es evidente que así ha de ser, dada la cantidad de información gramatical y normativa que aporta.

Finalizamos comentando un aspecto relacionado con el nivel de apropiación enunciativa (según el análisis de texto propuesto por Bronckart, 1997), con la forma de enunciar las consignas, dado que observamos lo que consideramos una particularidad de los manuales argentinos. En los niveles superiores (4 y 5 grado) se formula la consigna con distancia: modo imperativo y segunda persona, en la forma de Uds.: Relean, escriban, diseñen. Mientras que los del nivel inicial se enuncian con proximidad, utilizando el "vos": Releé, utilizá, ponele.

\section{Conclusión}

Las categorías de análisis que un enfoque comunicativo nos proporciona abarcan los dos órdenes de la comunicación lingüística: el de la expresión oral, con las habilidades de hablar y escuchar (comprensión oral), y el de la expresión escrita con las habilidades de leer y escribir. La puesta en relación de los datos rastreados en los manuales de lengua analizados nos permite afirmar que las actividades de expresión oral tienen mayor presencia de la que sospechábamos al iniciar este trabajo; pero también se observa que, en general, están poco planificadas. Los textos de las consignas hallados en los manuales constatan que estas habilidades quedan sugeridas (decimos sugeridas porque las tareas que las concretarían, por lo general, están poco pautadas), por lo que su trabajo en el aula queda librado a la voluntad de los docentes. Creemos que apenas son tenidas en cuenta al elaborar las consignas, y si se manifiestan es porque forman parte de la realidad comunicativa, lo que impide que se prescinda totalmente de ellas. Por lo tanto, es necesario un trabajo más sistematizado sobre estos aspectos para instaurarlos como objeto de enseñanza y liberarlos de la función subsidiaria de contribuir al desarrollo de otras habilidades (leer y escribir). En los manuales y, por lo tanto en la escuela, la habilidad de hablar está presente y es trabajada por los docentes, aunque de modo bastante espontáneo y poco sistematizado; mientras que la habilidad de escuchar, en su faceta de correlato del habla (como comprensión y/o registro mental de un texto oral) apenas se tiene en cuenta. Por tanto, consideramos que la primacía de lo escrito es una realidad; la comprensión de los textos es una de las finalidades de la enseñanza, pero se la relaciona en mayor medida con las actividad de expresión escrita: con la habilidad de leer (comprensión de un texto leído) y con la habilidad de escribir (manifestación escrita de la comprensión realizada y posibilidad de utilizar, citar, lo leído en un texto propio).

En cuanto a las actividades de expresión escrita, éstas son el fundamento del trabajo en todas las áreas y, en particular, en la de lengua. Pero, como los autores de los manuales analizados no las toman como actividades separadas, a menudo, aparecen un poquito mezcladas. 
Los manuales de lengua analizados pretenden la enseñanza tanto de nociones discursivas como gramaticales. Si bien son las discursivas las que organizan todos los libros analizados, concretamente la noción de género textual, la ejercitación propuesta se centra en las actividades gramaticales. En todos ellos se discrimina el trabajo sobre aspectos discursivo-textuales respecto de la normativa. Todos comienzan con una actividad de lectura, que propicia la presentación de modelos de distintos géneros textuales (literario y periodístico), y justifican la exposición de las nociones discursivas, para posteriormente proponer la realización de distintas actividades de escritura (elaboración de textos propios, completos y autónomos). También encontramos una serie de ejercicios sobre normativa y aspectos gramaticales, preámbulo de diversas nociones teóricas que se complementan con nueva ejercitación, lo que hace que la mayor cantidad de ejercicios registrados corresponda a actividades gramaticales.

Nos Ilama la atención la ausencia de registro bibliográfico al final de los manuales, cuando sabemos que es una práctica habitual en algunos grupos editoriales, pero no en los estudiados.

\section{REFERENCIAS BIBLIOGRÁFICAS}

ÁLVAREZ, J. M. (1998). "Didáctica general y didáctica específica", en A. Mendoza. Fillola (Ed.), Conceptos clave en didáctica de la lengua y la literatura (pp. 23-32). Barcelona, Horsori.

BRIZ, E. (1998). "La evaluación en el área de lengua y literatura", en A. Mendoza Fillola (Ed.), Conceptos clave en didáctica de la lengua y la literatura. Barcelona, Horsori.

BRONCKART, J.-P. (1997). Activité langagière, textes et discours. Pour un interactionisme socio-discursif. Paris, Delachaux et Niestlé.

BROWARNIK, G., et al. (2005). Puerto manual 4. Artesanal. Conectado. Buenos Aires, Puerto de Palos.

CANO, F. et al. (2007). Lengua 5. Serie Entender-Segundo ciclo. Buenos Aires, Estrada.

DOLZ, J. y GAGNON, R. (2008). "Le genre du texte, un outil didactique pour développer le langage oral et écrit". Pratiques, 137-138, pp. 179-198.

DOLZ, J. y SCHNEUWLY, B. (1997). "Géneros y progresión en expresión oral y escrita". Textos, 11, pp. 77-98.

EDICIONES SANTILLANA, (2006). Luna lunera 3. Buenos Aires, Santillana.

ERARD, S. y SCHNEUWLY, B. (2005). "La didactique de l'oral: savoirs ou compétences?", en J.-P. Bronckart (Ed.), Repenser l'enseignement des langues: comment identifier et exploiter les compétences (pp. 69-97). Presses Universitaire du Septentrión, Villeneuve d'Ascq cedes.

LEONTIEV, A. (1983). El desarrollo del psiquismo. Madrid, Akal.

MENDOZA FILLOLA, A. (1998). Conceptos clave en didáctica de la lengua y la literatura. Barcelona, Horsori.

RIESTRA, D. (1999). "Reenseñar la escritura a estudiantes universitarios". Fundación Infancia y Aprendizaje, 88, pp. 43-56. 
RIESTRA, D. (2000). "Análisis de la enseñanza de la lengua materna desde la teoría de la actividad". III Conference for Sociocultural Research, Campinas, Brasil [cdrom]. RIESTRA, D. (2006). Usos y formas de la lengua escrita. Buenos Aires, Novedades Educativas.

RIESTRA, D. (2008), Las consignas de enseñanza de la lengua. Buenos Aires, Miño y Dávila.

SARCEDA, M. S. (1998). Historias en bicicleta. Lectura y escritura con áreas integradas, Buenos Aires, Kapelusz ( $3^{\circ}$ de nivel primario).

SCHNEUWLY, B. (1997), "La enseñanza del lenguaje oral y la lectoescritura en la perspectiva socio-cultural", en Amelia Álvarez (Ed.), Hacia un currículum cultura. La vigencia de Vygotski en la educación (pp. 91-100). Madrid: Fundación Infancia y Aprendizaje. 


\section{ANEXo}
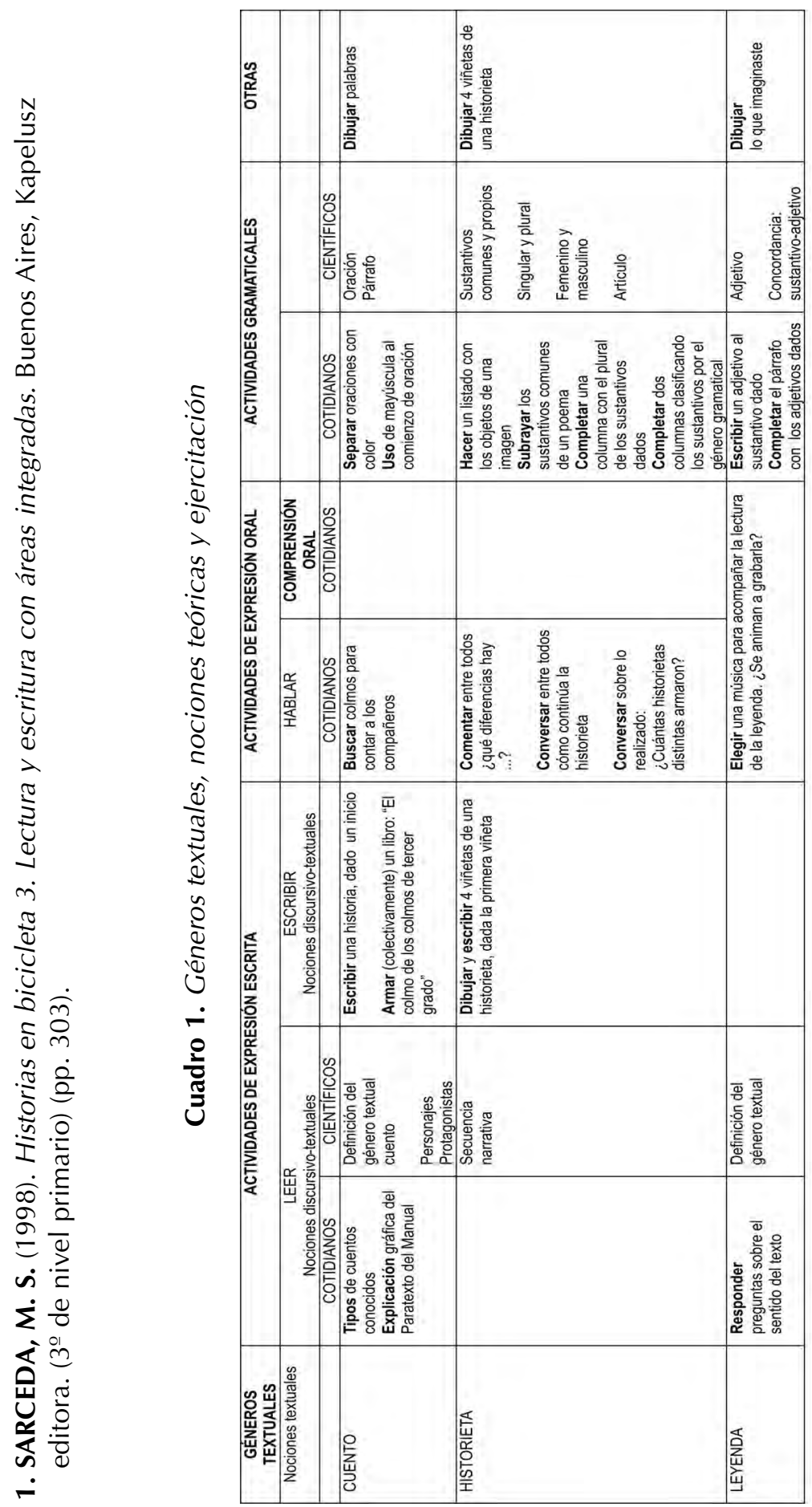


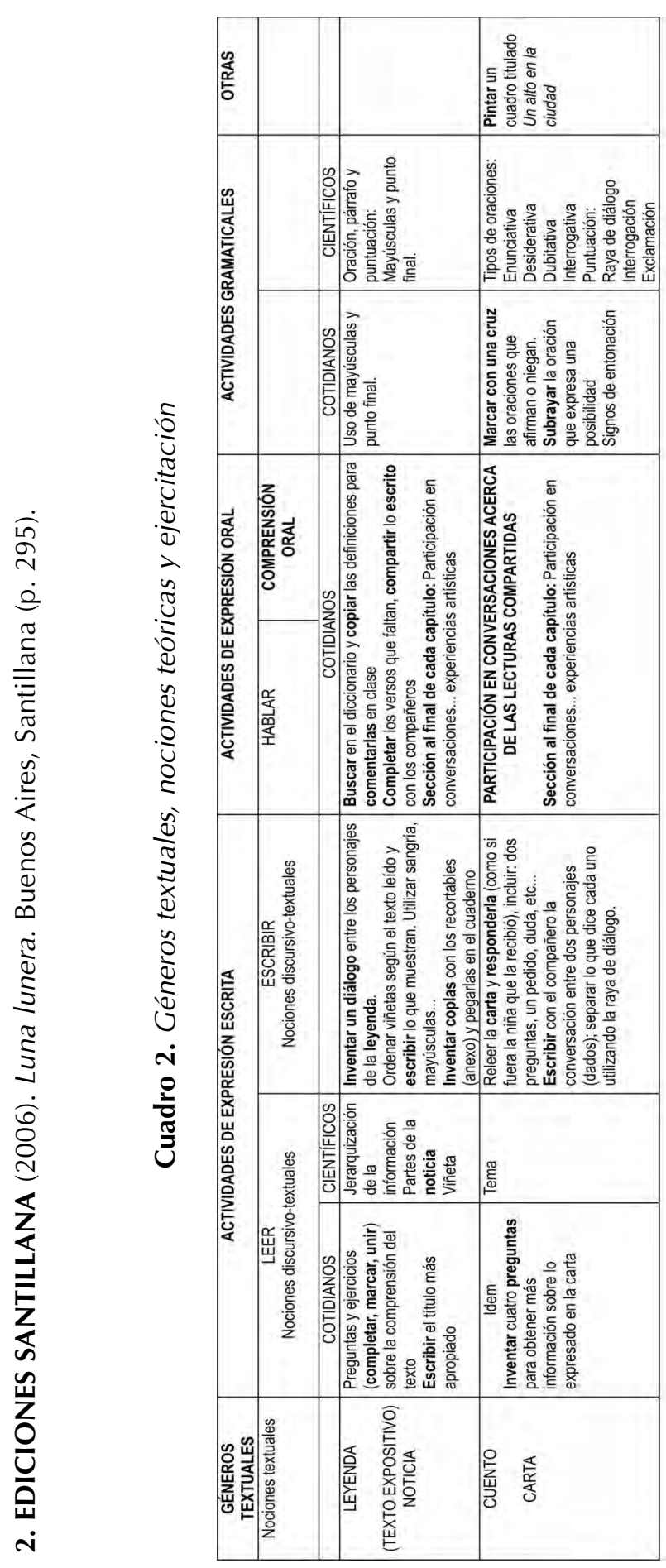




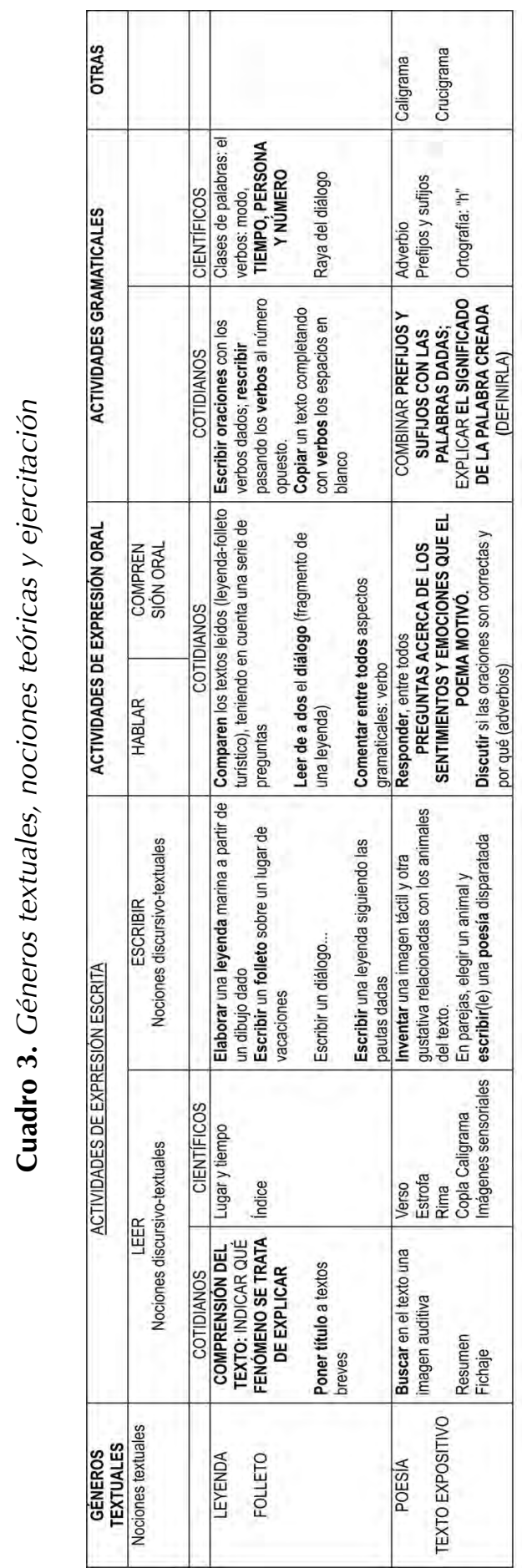



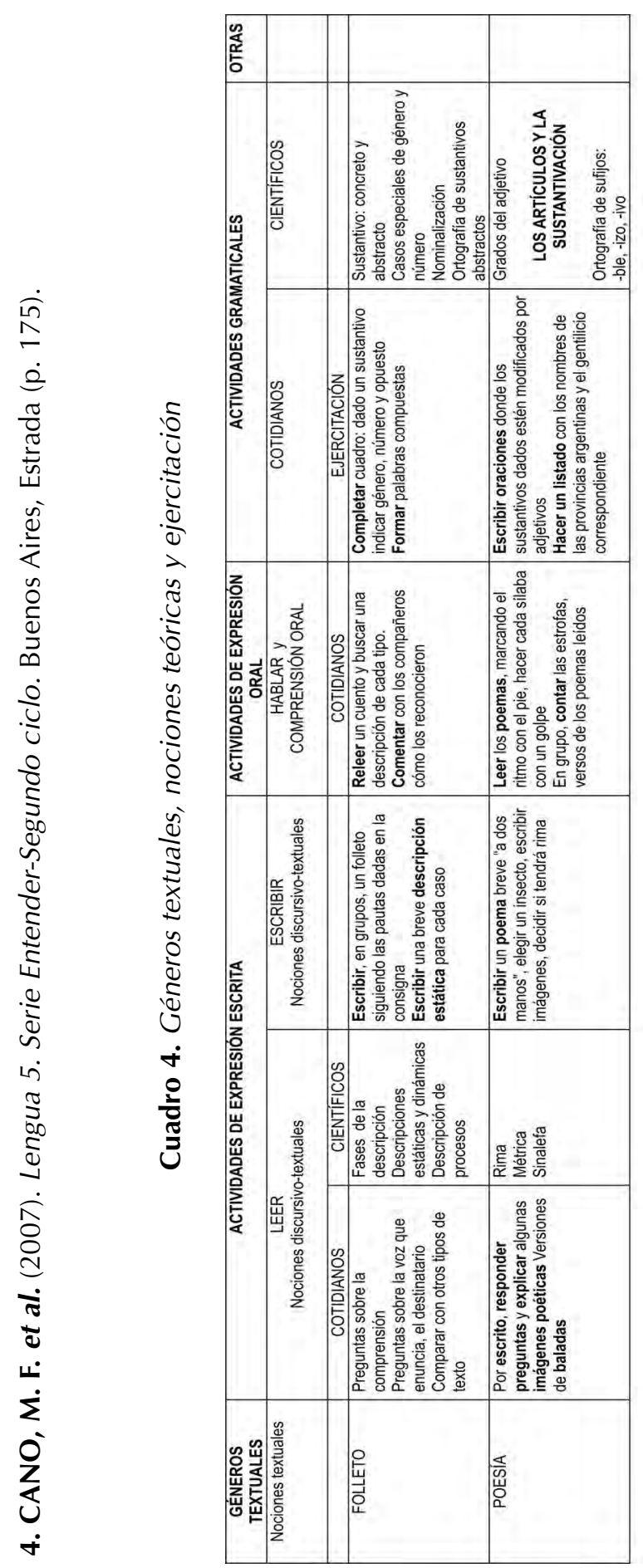